\title{
A Smart Chemosensor: Discriminated Multidetection and Execution of Various logic Gates in Aqueous Solution at Biological pH
}

\author{
Awad I. Said $^{1}$, Nikolai l. Georgiev², Vladimir B. Bojinov ${ }^{2}$ \\ ${ }^{1}$ Department of Chemistry, Faculty of Science, Assiut University, Assiut, Egypt, \\ ${ }^{2}$ Department of Organic Synthesis, University of Chemical Technology and Metallurgy, Sofia, Bulgaria \\ Corresponding author awadsaid@aun.edu.eg
}

\begin{abstract}
:
A novel rhodamine and pyrazole based probe was designed and easily synthesized. The probe could to detect several analyts in aqueous solution at biological pH (HEPES, 7.2). the probe could to detect discrimintly Several catoions, including $\mathrm{Cu}^{2+}, \mathrm{Fe}^{3+}, \mathrm{Al}^{3}, \mathrm{Hg}^{2+}$ and $\mathrm{Ni}^{2+}$. The detection could be selective towards $\mathrm{Cu}^{2+}$ by using high concentration of HEPES $\left(10^{-3} \mathrm{~mole}^{-1}\right)$ in aquous solution and could be selective towards $\mathrm{Hg}^{2+}$ (by absorption spectrum) by working in pure organic medium (acetonitrile). By low concentration of HEPES buffer and one equivalent of cation, $\mathrm{Fe}^{3+}$ was discrimined by the enhancement of both the absorption at $530 \mathrm{~nm}$ and emission at $560 \mathrm{~nm}$, but $\mathrm{Al}^{3+}$ enhanced only the emission at $560 \mathrm{~nm}$ remarkably (high quantum yield). $\mathrm{Ni}^{2+}$ could to be discriminated by increaing both absorption and emission after using ten equivalents of $\mathrm{Ni}^{2+}$ and low concentration of HEPES $\left(10^{-5}\right.$ mole $\left.\mathrm{L}^{-1}\right)$. Also, the probe exhibited a good selectivity towards $\mathrm{S}_{2} \mathrm{O}_{5}{ }^{2-}$ by both absorption and emission spectra. Moreover, probe- $\mathrm{Cu}^{2+}$ complex could to detect several anions, including $\mathrm{F}^{-}, \mathrm{CN}^{-} . \mathrm{S}^{2-}, \mathrm{CH}_{3} \mathrm{COO}^{-}, \mathrm{CO}_{3}{ }^{2-}, \mathrm{NO}_{2}^{-}$. A further exploition of the prepared probe, is its ablility to work as a molecular logic gate to perform many gates including AND, NAND, NOR and INHIBIT logic gates.
\end{abstract}

Key words: Probe, Fluorescence, cations, anions, logic gates, smart probe.

\section{References:}

1- V. Bojinov, A. Venkova, N. Georgiev, "Synthesis and energy-transfer properties of fluorescence sensing bichromophoric system based on Rhodamine 6G and 1,8-naphthalimide", Sensors Actuators B: Chem, 143 (2009), pp. $42-49$

2- A. Said, N. Georgiev, V. Bojinov "Sensor activity and logic behavior of dihydroxyphenyl hydrazone derivative as a chemosensor for $\mathrm{Cu}^{2+}$ determination in alkaline aqueous solutions" $J$. Photochem. Photobiol. A Chem., 311 (2015), pp. 16-24.

3- Orrego-Hernandez, Jessica; Portilla, Jaime, "Synthesis of Dicyanovinyl-Substituted 1-(2-Pyridyl) pyrazoles: Design of a Fluorescent Chemosensor for Selective Recognition of Cyanide", Journal of Organic Chemistry (2017), 82(24), 13376-13385. 